\title{
Developmental programming: postnatal estradiol modulation of prenatally organized reproductive neuroendocrine function in sheep
}

\author{
Muraly Puttabyatappa, Rodolfo C Cardoso, Carol Herkimer, Almudena Veiga-Lopez ${ }^{\dagger}$ and \\ Vasantha Padmanabhan \\ Department of Pediatrics, University of Michigan, Ann Arbor, Michigan, USA \\ Correspondence should be addressed to V Padmanabhan; Email: vasantha@umich.edu \\ ${ }^{\dagger}$ (A Veiga-Lopez is now at the Department of Animal Sciences, Michigan State University, East Lansing, Michigan, USA)
}

\begin{abstract}
Gestational testosterone (TS) excess, acting via both the androgenic and estrogenic pathways, advances puberty and disrupts the neuroendocrine estradiol $\left(E_{2}\right)$ feedback and periovulatory hormonal dynamics in female sheep. These prenatally programmed defects may be subject to postnatal modifications by continued organizational and/or activational effects of steroids. This study investigated (1) the organizational contribution of prenatal estrogen excess and (2) the impact of postnatal exposure to $E_{2}$ in modulating the effects of prenatal androgen excess (TS and dihydrotestosterone (DHT)) on puberty, neuroendocrine feedback mechanisms, and periovulatory hormonal dynamics in sheep. Pregnant Suffolk sheep were treated with TS, DHT, $E_{2}$, or $E_{2}$ plus DHT (ED) from days 30 to 90 of gestation. A subset of the control (C), TS, and DHT female offspring received a constant-release $E_{2}$ implant postnatally. Findings revealed that (1) prenatal $E_{2}$-treatment failed to reproduce the neuroendocrine disruptions predicted to be programmed by the estrogenic pathway and (2) prenatal $E_{2} D$-treatment did not adequately replicate the reproductive neuroendocrine defects induced by prenatal TS excess. More importantly, continuous postnatal $E_{2}$-treatment, while delaying the onset of puberty and reducing the inhibitory effects of $E_{2}$ on tonic luteinizing hormone (LH) release, failed to amplify the $E_{2}$-positive feedback and periovulatory defects induced by prenatal TS-treatment. Our results indicate that disruptions in $E_{2}$-positive feedback mechanisms and periovulatory gonadotropin secretion induced by prenatal TS-treatment are programmed predominantly during the prenatal life with postnatal exposure to $E_{2}$ excess not contributing further to these disruptions.

Reproduction (2016) 152 139-150
\end{abstract}

\section{Introduction}

Many diseases in adults, such as obesity, metabolic syndrome, and polycystic ovary syndrome (PCOS), may have their origins during fetal life. As proposed by Barker's developmental origins of adult disease hypothesis (Barker 2004), adverse prenatal insults can cause permanent changes in the physiology of the developing fetus leading to pathology during adulthood. These insults include inadvertent exposure to hormonal, nutritional, and environmental agents (Rhind et al. 2001, Tang \& Ho 2007, Dumesic et al. 2014). The effects of increased exposure to native steroids in disease states (New 2006, Rosenfield 2007) and to environmental endocrine-disrupting chemicals (EDC) that can bind to steroid receptors (Vaiserman 2014) have been the focus of intense research. Due to the high rate of tissue differentiation and metabolism, a developing fetus is extremely sensitive to EDC exposures even at concentrations far below those detrimental to adults (Diamanti-Kandarakis et al. 2009, Schug et al. 2011).

Congenital adrenal hyperplasia (CAH) (New 2006) and PCOS (Sir-Petermann et al. 2002) are disease states characterized by elevated testosterone levels, among other endocrine imbalances. Experimentally, prenatal TS-treatment in various species, including sheep, leads to dysfunctions during adult life that resemble those seen in women with PCOS (Padmanabhan \& Veiga-Lopez 2013a,b, Dumesic et al. 2014). For instance, prenatal TS-treated sheep show progressive loss of cyclicity (Clarke et al. 1977, Birch et al. 2003, Manikkam et al. 2006) and disrupted periovulatory hormonal dynamics (Veiga-Lopez et al. 2008), with defects evident at both the neuroendocrine and ovarian levels (Padmanabhan \& Veiga-Lopez 2013b). The neuroendocrine disruptions induced by prenatal TS excess include reduced sensitivity to estradiol $\left(\mathrm{E}_{2}\right)$ and progesterone $(\mathrm{P})$ negative feedback (Wood \& Foster 1998, Robinson et al. 2002, 
Sarma et al. 2005), dampened or absent $E_{2}$-positive feedback, and disrupted periovulatory hormonal dynamics (Sharma et al. 2002, Unsworth et al. 2005, Veiga-Lopez et al. 2009). Comparative studies with dihydrotestosterone (DHT), a nonaromatizable androgen (Veiga-Lopez et al. 2009), as well as TS+ androgen antagonist-treated sheep (Jackson et al. 2008) provided evidence that $E_{2}$-negative, but not $E_{2}$-positive, feedback perturbations are programmed by androgenic actions of TS. This led to the premise that $E_{2}$-positive feedback and periovulatory hormonal dynamics are likely programmed by the estrogenic actions of TS (Foster et al. 2006).

Although the organizational period may extend beyond birth (Jackson et al. 2013), evidence suggests that activational effects of the postnatal environment can modify the impact of such organizational changes. For instance, the organizational effects of excess prenatal steroid hormone exposure in masculinizing the behavioral circuits in the males become only apparent during puberty when gonadal steroid output determines the expression of sex-typical behavior (Schulz et al. 2009). This can be explained by the two-hit hypothesis, which states that an early-life adverse event ("first-hit") programs a pathological condition that may be revealed only later in life by a subsequent exposure to an adverse influence or the so-called "second hit" (Bayer et al. 1999, Tang et al. 2008, Puttabyatappa et al. 2015). From an adverse exposure standpoint, humans are exposed throughout their lifespan to steroids involuntarily and sometimes unknowingly through food consumption (phytoestrogens), industrial byproducts (bisphenol A), diseases (CAH, PCOS), and/or voluntarily (contraception and anabolic steroids) (Bahrke et al. 1998, Jefferson et al. 2012, Pignatelli 2013, Peretz et al. 2014, Jensen et al. 2015). Such exposure(s) can be deleterious to fertility and may serve to mask/unmask or reduce/amplify prenatally programmed functions. For example, postnatal overfeeding (second hit) of prenatally TS-treated (first hit) sheep exacerbated the reproductive cyclicity defects, with a majority of animals ending their breeding season early (Steckler et al. 2009). Similarly, postnatal exposure to $E_{2}$ (second hit) amplified the ovarian defects induced by prenatal TS excess (first hit) (Veiga-Lopez et al. 2014).

The objective of this study was to investigate the contributions of prenatal and postnatal $E_{2}$ in programming and amplifying reproductive neuroendocrine defects. Specifically, this study tested the following hypotheses: (1) prenatal $E_{2}$-treatment alone induces neuroendocrine defects that have been postulated to be programmed by the estrogenic effects of prenatal TS-treatment, (2) prenatal ED-treatment replicates the effects of prenatal TS-treatment, and (3) continuous postnatal $E_{2}$ exposure amplifies the effects of prenatal androgen excess.

\section{Materials and methods}

All procedures used in this study were approved by the University of Michigan Animal Care and Use Committee and are consistent with the National Research Council's Guide for the Care and Use of Laboratory Animals.

\section{Generation of experimental animals}

The study was conducted at the University of Michigan Sheep Research Facility, Ann Arbor, MI, USA. Adult Suffolk ewes purchased from local farmers were mated with Suffolk rams of proven fertility. General husbandry and nutrition have been described previously (Manikkam et al. 2004). Starting at 2-3 weeks before breeding, ewes were groupfed daily with $0.5 \mathrm{~kg}$ shelled corn and $1.0-1.5 \mathrm{~kg}$ alfalfa hay/ewe. Once mated, females were assigned randomly to the different treatment groups and housed under a natural photoperiod in the pasture and group-fed with a daily maintenance diet of $1.25 \mathrm{~kg}$ alfalfa/brome mix hay/ewe. Lambs born to these ewes were fed a pelleted diet (Shur-Gain, Strykersville, NY, USA) consisting of $3.6 \mathrm{MCal} / \mathrm{kg}$ digestible energy and $18 \%$ crude protein. At $\sim 8$ weeks of age, lambs were weaned and maintained outdoors. They were fed ad libitum until they attained $\sim 40 \mathrm{~kg}$ of body weight, at which point they were switched to a diet consisting of $2.3 \mathrm{MCal} / \mathrm{kg}$ digestible energy and $11.3 \%$ crude protein. The treatment groups used in the study and the various studies performed are summarized in Fig. 1.

The lambs used in the study received either no treatment prenatally (control; $\mathrm{C}$ ) or were treated prenatally from gestational days 30 to 90 with TS (TS-treated), DHT (D-treated), estradiol $\left(E_{2}\right.$-treated), or $E D$ (ED-treated) (Fig. 1A). The number of female offspring born in each treatment group was $C=13, E_{2}=11$, $\mathrm{ED}=6$ and 7 each for TS and $\mathrm{D}$ prenatal treatment groups. A subset of prenatal C, TS-, and D-treated females received $\mathrm{E}_{2}$ implants postnatally starting at $\sim 12$ weeks of age. Sample size of postnatal groups was 7 for $C+E_{2}$ and $T S+E_{2}$, and 6 for the $D+E$ group (Fig. 1A). There were insufficient animals to generate postnatal treatment groups from prenatal $E_{2}$ - and ED-treated animals. Changes in ovarian follicular dynamics in this cohort of animals have been reported previously (Veiga-Lopez et al. 2014).

\section{Prenatal groups}

Prenatal TS- and D-treated female sheep were generated as reported previously (Wood et al. 1991). Briefly, pregnant Suffolk ewes were injected (intramuscular) twice weekly from 30 to 90 days of gestation with either $100 \mathrm{mg}$ TS propionate $(1.2 \mathrm{mg} / \mathrm{kg}$; Sigma-Aldrich) or $100 \mathrm{mg}$ DHT propionate (Steraloids, Newport, RI, USA) suspended in $2 \mathrm{~mL}$ cottonseed oil. Females in the $C$ group did not receive vehicle because no differences in reproductive parameters were found between vehicle-treated and untreated controls in our previous study (Veiga-Lopez et al. 2008). Prenatal $\mathrm{E}_{2}$-treated animals were generated by placing a $30 \mathrm{~mm}$ SILASTIC implant (Dow Corning, Midland, MI, USA) filled with crystalline $\mathrm{E}_{2}$ subcutaneously in the axillary region for the same duration as described before 
A

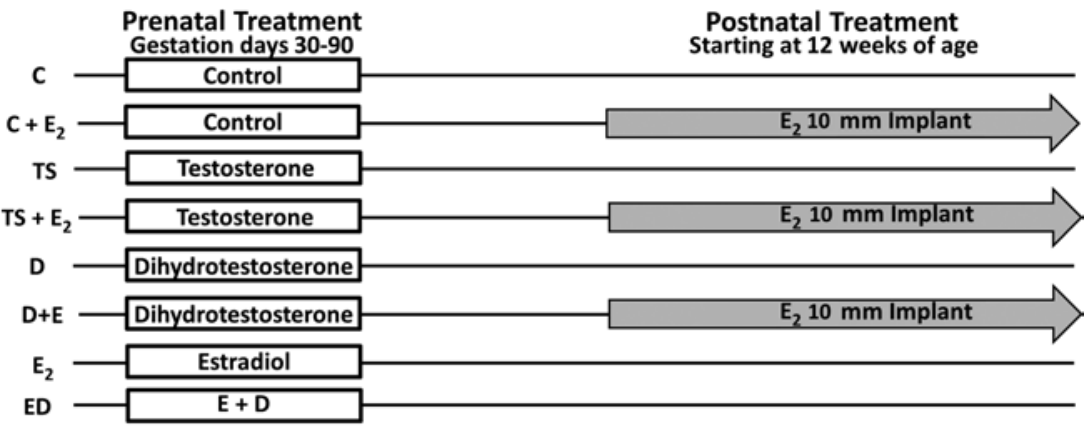

B
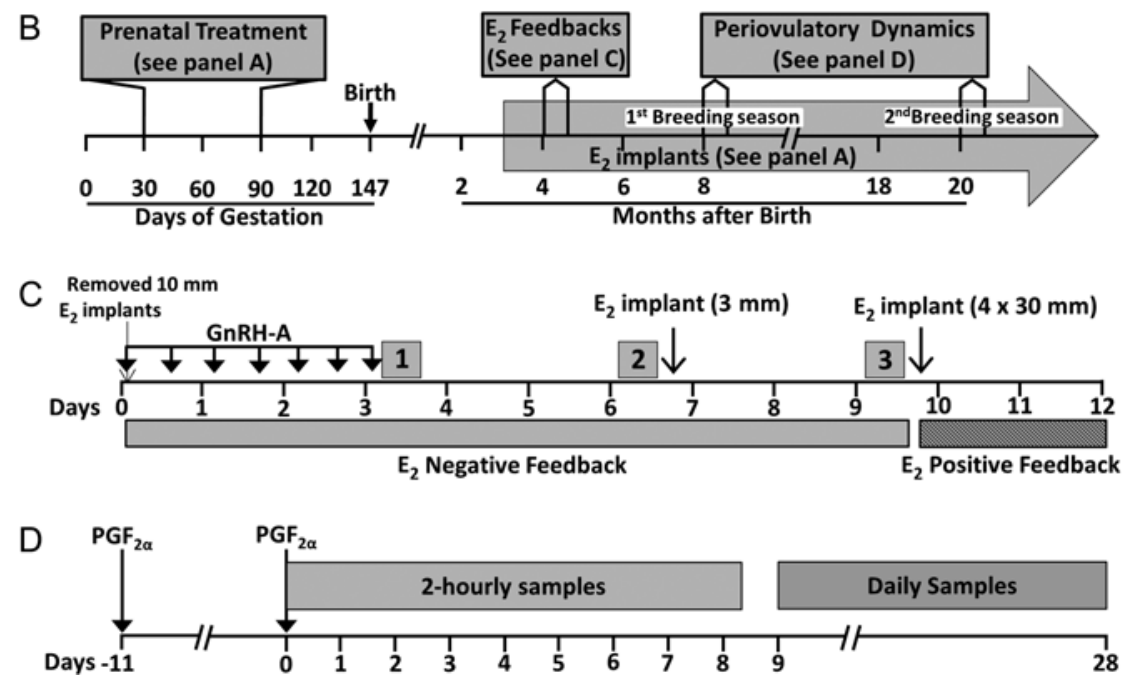

Figure 1 Schematic showing the study design. (A) Prenatal and postnatal treatment groups. (B) Timeline of studies carried out. (C) Timeline of the $E_{2}$-negative and $E_{2}$ positive feedback studies. Periods 1,2 , and 3 indicate pulse bleed at the end of the $\mathrm{GnRH}-\mathrm{A}$ treatment, $72 \mathrm{~h}$ after cessation of the $\mathrm{GnRH}-\mathrm{A}\left(\right.$ Pre- $\mathrm{E}_{2}$ ) treatment and $72 \mathrm{~h}$ after the $E_{2}$-treatment (Post- $E_{2}$ ) respectively. Hatched bar indicates timing of $E_{2}$-positive feedback. (D) Timeline of the assessment of the periovulatory hormonal dynamics carried out during the first and second breeding seasons. Arrows indicate the time of estrous synchronization with $\mathrm{PGF}_{2 \alpha}$ injections and gray boxes show periods of 2-hourly samples and daily sample collection.
(Jackson et al. 2008). Control females did not receive sham implants. The efficacy of this approach in suppressing $\mathrm{LH}$ secretion in sheep has been well established (Karsch et al. 1993). The $30 \mathrm{~mm}$ implant produces circulating $\mathrm{E}_{2}$ concentrations of $\sim 3 \mathrm{pg} / \mathrm{mL}$, similar to those seen during the follicular phase in the female sheep (Goodman et al. 1980, 1981, Jackson et al. 2013). The prenatal ED-treated group received $E_{2}$ implants along with twice weekly injections of DHT.

\section{Postnatal treatment}

Approximately 12 weeks after birth, half of the prenatal $\mathrm{C}_{-}, \mathrm{TS}-$, and D-treated female lambs received $10 \mathrm{~mm} \mathrm{E}_{2}$ implants, which produces circulating concentrations of $E_{2}$ at $\sim 1 \mathrm{pg} / \mathrm{mL}$ (Goodman et al. 1980, 1981, Jackson et al. 2013). Figure 1 summarizes the treatment groups and the type and sequence of studies conducted.

\section{Assessment of puberty}

Beginning at $\sim 21$ weeks of age, $\mathrm{P}$ concentrations in blood samples collected twice a week were assessed in all animals. Age at puberty was defined as the age at the first sample having circulating concentrations of $P$ greater than $0.5 \mathrm{ng} / \mathrm{mL}$.

\section{Testing $E_{2}$-negative feedback responses}

This test was conducted during the prepubertal period ( 18 weeks of age; Fig. 1B), when female lambs are extremely sensitive to the $E_{2}$-negative feedback (Foster \& Jackson 2006). Details of the $E_{2}$-negative feedback test are summarized in Fig. 1C. The gonadotropin-releasing hormone antagonist (GnRH-A), acyline (Contraception and Reproductive Health Branch, National Institutes of Health, Bethesda, MD, USA), was administered subcutaneously $(10 \mu \mathrm{g} / \mathrm{kg})$ every $12 \mathrm{~h}$ for $72 \mathrm{~h}$ to abolish $\mathrm{LH}$ pulsatility and reduce endogenous $\mathrm{E}_{2}$ concentrations (Sarma et al. 2005, Steckler et al. 2008). Blood samples were collected at 20 min intervals for $6 \mathrm{~h}$ after the last GnRH-A injection to determine the GnRH-A ablation of LH pulsatility (Period 1; Fig. 1C). To establish the impact of reduced endogenous $\mathrm{E}_{2}$ on $\mathrm{LH}$ pulse frequency, blood samples were collected for $6 \mathrm{~h}$ beginning $72 \mathrm{~h}$ after cessation of the GnRH-A treatment (Period 2; Pre $\mathrm{E}_{2}$; Fig. 1C). The $\mathrm{E}_{2}$-negative feedback was then evaluated by inserting a single $3 \mathrm{~mm}$ SILASTIC $E_{2}$ implant (subcutaneously) to produce circulating concentrations of $<1 \mathrm{pg} / \mathrm{mL}$ (Goodman et al. 1980, 1981, Jackson et al. 2013). Blood samples were collected beginning $72 \mathrm{~h}$ after insertion of the $\mathrm{E}_{2}$ implant for $6 \mathrm{~h}$ at $20 \mathrm{~min}$ intervals (Period 3; Post $\mathrm{E}_{2}$; Fig. 1C).

\section{Testing $\boldsymbol{E}_{2}$-positive feedback responses}

This test was carried out following the $E_{2}$-negative feedback testing (Fig. 1C) in prepubertal females at $\sim 19$ weeks of age in the absence of $\mathrm{P}$ priming, as reported previously (Sharma et al. 2002). All animals received four $30 \mathrm{~mm}$ SILASTIC $E_{2}$ 
implants (subcutaneously) to provide late follicular phase concentrations of $\mathrm{E}_{2}$ (Goodman et al. 1980, 1981, Jackson et al. 2013). Blood samples were collected every $2 \mathrm{~h}$ for $72 \mathrm{~h}$ starting $1 \mathrm{~h}$ before insertion of $\mathrm{E}_{2}$ implants.

\section{Periovulatory hormonal dynamics}

The impact of experimental treatments on periovulatory hormonal dynamics was studied during the first and second breeding season at $\sim 8$ and $\sim 20$ months of age respectively (Fig. 1B). Studies were carried out during two breeding seasons to determine whether these animals show a progressive loss in cyclicity as observed previously in prenatal TS-treated animals (Manikkam et al. 2006). Estrous was synchronized with two injections of prostaglandin $\mathrm{F}_{2 \alpha}\left(\mathrm{PGF}_{2 \alpha^{\prime}} 10 \mathrm{mg}\right.$, intramuscular; Lutalyse, Pfizer Animal Health, Florham Park, NJ, USA) administered 11 days apart (Fig. 1D). Following the second $\mathrm{PGF}_{2 \alpha}$ injection, blood samples were collected every $2 \mathrm{~h}$ for $192 \mathrm{~h}$ during the first breeding season and for $120 \mathrm{~h}$ during the second breeding season to assess the periovulatory hormonal changes. This was followed by daily blood sampling for 19 additional days to assess luteal $\mathrm{P}$ secretion. $\mathrm{LH}$ and $\mathrm{FSH}$ were assayed every $2 h, E_{2}$ every $4 h$, and $P$ in daily samples.

\section{Hormone measurements}

Plasma LH, FSH and $\mathrm{P}$ concentrations were measured in duplicate using validated radioimmunoassays (RIA) (Niswender et al. 1969, Padmanabhan et al. 1995, 1997). The sensitivity of LH RIA was $0.1 \pm 0.01 \mathrm{ng} / \mathrm{mL}$ ( $n=46$ assays; mean \pm S.E.M.). Mean intra-assay coefficient of variation $(\mathrm{CV})$ based on four quality control pools measuring $3.1 \pm 0.1,7.2 \pm 0.1,13.4 \pm 0.1$, and $23.8 \pm 0.01 \mathrm{ng} / \mathrm{mL}$ were $10.0,6.0,6.8$, and $6.0 \%$ respectively. The corresponding interassay CVs averaged 20.5, 7.2, 5.6, and $4.5 \%$. The sensitivity of FSH RIA was $0.06 \pm 0.01 \mathrm{ng} / \mathrm{mL}(n=31$ assays). The intra-assay $\mathrm{CV}$ s based on two quality control pools measuring $5.0 \pm 0.1$ and $11.2 \pm 0.2 \mathrm{ng} / \mathrm{mL}$ were 9.9 and $4.8 \%$ respectively. The corresponding interassay CVs averaged 13.9 and $8.7 \%$. Plasma $E_{2}$ for the $E_{2}$-negative feedback study was measured using the commercially available MAIA kit (Polymedco Inc., Courtlandt Manor, NY) and for the periovulatory hormonal dynamics assessment was measured using a validated RIA (Rozell \& Keisler 1990). For the MAIA kit sensitivity of $E_{2}$ assay was $0.1 \pm 0.02 \mathrm{pg} / \mathrm{mL}$ ( $n=6$ assays). Mean intra-assay CVs based on two quality control pools measuring $1.09 \pm 0.08$ and $5.30 \pm 0.054 \mathrm{pg} / \mathrm{mL}$ was 14.22 and $13.76 \%$ and the corresponding inter-assay CVs averaged $17.02 \& 24.59 \%$. For the periovulatory hormonal dynamics study sensitivity of $E_{2}$ RIA was $0.3 \pm 0.1 \mathrm{pg} /$ $\mathrm{mL}$ ( $n=36$ assays). Mean intra-assay $\mathrm{CVs}$ based on two quality control pools measuring $0.53 \pm 0.02$ and $3.32 \pm 0.15 \mathrm{pg} / \mathrm{mL}$ were 12.8 and $12.6 \%$, respectively. The corresponding interassay CVs averaged 18.36 and $25.38 \%$. The sensitivity of P RIA (Coat-a-Count, DPC/Siemens) was $0.001 \pm 0.0002 \mathrm{ng} / \mathrm{mL}(n=8$ assays). Mean intra-assay $\mathrm{CVs}$ based on three quality control pools measuring $0.2 \pm 0.006,1.7 \pm 0.02$, and $14.3 \pm 0.2 \mathrm{ng} / \mathrm{mL}$ were $4.8,5.1$, and $2.4 \%$ respectively. The corresponding interassay CVs averaged 12.2, 3.6, and 3.8\%. Sample sets from experimental groups were randomly distributed such that each assay included samples from all treatment groups.

\section{Statistical analysis}

Age at puberty was assessed in all animals. Results from twin females were averaged for assessment of puberty before analysis to ensure mother was the experimental unit. Only a subset of animals was used for $E_{2}$-negative and $E_{2}$-positive feedback studies ( $n=7$ each for C, TS, D, $\mathrm{E}_{2}, \mathrm{C}+\mathrm{E}_{2}$, and TS $+\mathrm{E}_{2}$, and $n=6$ each for $E D$ and $D+E$ ) and for assessment of periovulatory hormonal dynamics $\left(n=6\right.$ each for C, TS, D, ED, C $+\mathrm{E}_{2}$, and $\mathrm{D}+\mathrm{E}$ groups, $n=7$ for $\mathrm{E}_{2}$ and $n=5$ for $\mathrm{TS}+\mathrm{E}_{2}$ ). During the second breeding season, only animals from $C$, TS, and $E_{2}$ for prenatal treatment groups and $C+E_{2}$ and $T S+E_{2}$ for postnatal groups were available for this study. The number of animals in each treatment group during their second year were $\mathrm{C}=9$, $\mathrm{TS}=5, \mathrm{E}_{2}=9, \mathrm{C}+\mathrm{E}_{2}=7$, and $\mathrm{TS}+\mathrm{E}_{2}=4$. For the feedback and periovulatory dynamic studies, when twin female births were involved, only one offspring (selected randomly) was used.

For $\mathrm{E}_{2}$-negative feedback, LH values from serially collected samples were subjected to pulse analysis using the cluster algorithm (Veldhuis \& Johnson 1986). For cluster analysis, the minimum number of data points to identify either a peak (the highest concentration reached during a pulse) or a nadir (basal level) for the $20 \mathrm{~min}$ sampling frequency was set at one. The Student's $t$ statistic values used to identify significant increases from preceding nadirs and decreases to following nadirs were set at 1.0. Increases in LH concentrations more than two times the assay sensitivity over the preceding nadir were considered as a pulse. The number of pulses was assessed over a $6 \mathrm{~h}$ period. For both $\mathrm{E}_{2}$-positive feedback and periovulatory hormonal characterization, the $\mathrm{LH}$ and $\mathrm{FSH}$ surges were defined based on the circulating gonadotropin concentrations being above the baseline plus two times the assay sensitivity and remaining high for at least $8 \mathrm{~h}$ (Padmanabhan et al. 2015). For synchronization of the estrous cycle following $\mathrm{PGF}_{2 \alpha}$ injection, daily $\mathrm{P}$ concentrations had to fall below $0.5 \mathrm{ng} / \mathrm{mL}$. For all statistical analysis, $P<0.05$ was considered significantly different.

\section{Age at puberty}

The age at puberty was analyzed by one-way ANOVA for prenatal treatment group comparisons and a two-way ANOVA for testing postnatal $E_{2}$ modulation. In view of the large number of comparisons that reduces power, the magnitude of treatment effects on age at puberty was also examined by effect size analysis (Cohen 1992, Nakagawa \& Cuthill 2007, Padmanabhan et al. 2015). This analysis allows comparison of the means between two treatments with respect to the magnitude of difference between them. The computed statistic is Cohen's $d$ value, and values above $0.2,0.5$, and 0.8 were considered as small, medium, and large effect sizes, respectively (Cohen 1992, Nakagawa \& Cuthill 2007).

\section{$E_{2}$-negative feedback}

Variables compared were $\mathrm{E}_{2}$ concentrations and $\mathrm{LH}$ pulse frequency. Number of pulses during the $6 \mathrm{~h}$ period was squareroot-transformed before analysis. For comparison among prenatal groups, ANOVA was used followed by post hoc analyses adjusting for multiple comparisons. For postnatal 

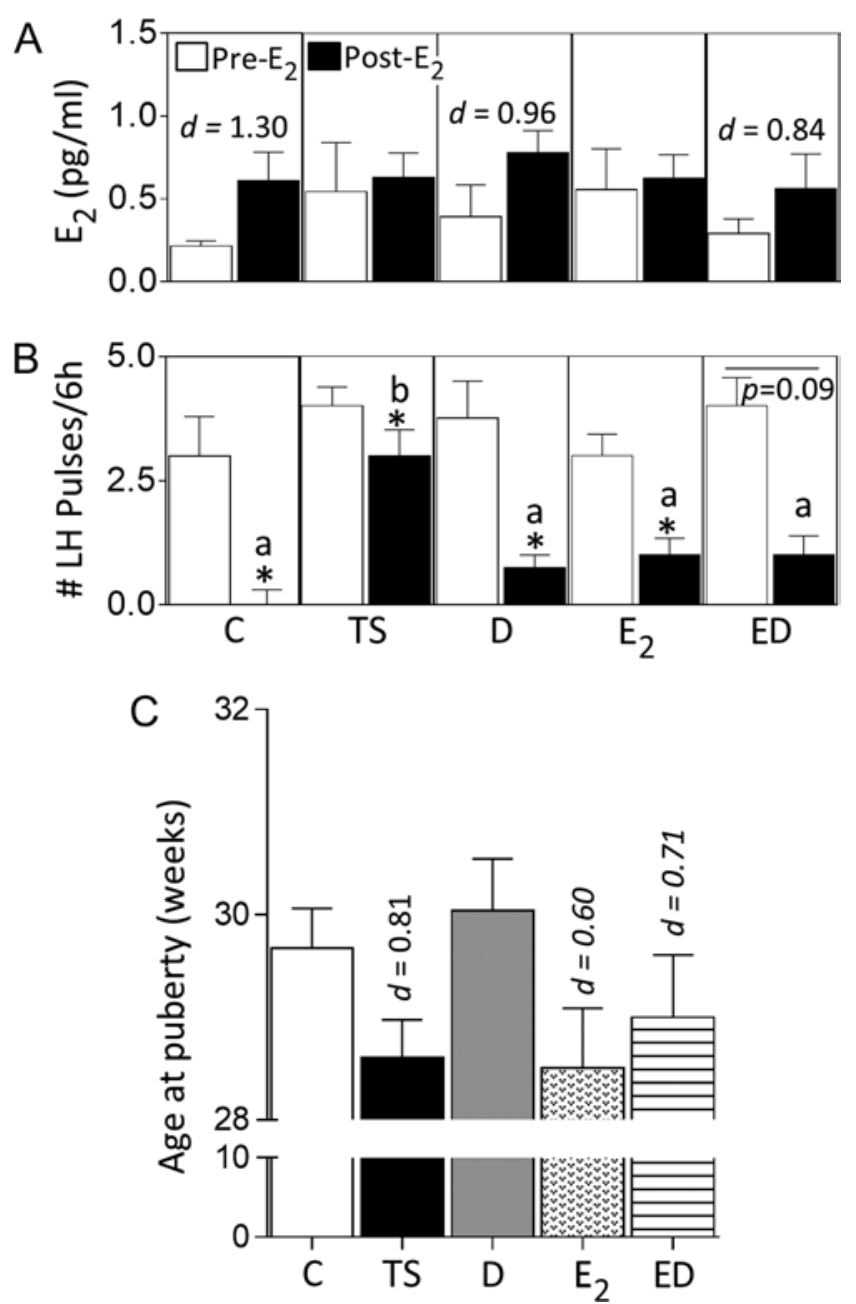

Figure 2 Results (mean \pm S.E.M.) of the $\mathrm{E}_{2}$-negative feedback test in prenatal groups are shown in panels $\mathrm{A}$ and $\mathrm{B}$ and age of puberty in panel $C$. Panel $A$ shows the circulating concentrations of $E_{2}$ pre- and post- $\mathrm{E}_{2}$ administration. Panel $\mathrm{B}$ shows the number of $\mathrm{LH}$ pulses over a 6-h period pre- and post- $E_{2}$ administration. Asterisks indicate significant difference $(P<0.05)$ within the respective prenatal treatments. Bars with different superscripts in the post- $E_{2}$ period in panel $\mathrm{B}$ are significantly different. Panel $\mathrm{C}$ shows age of puberty in weeks. Cohen's $d$ values as determined by effect size analysis are shown in panels $A$ (Pre $E_{2}$ vs Post $E_{2}$ ) and $C$ (prenatal treatment vs $C$ ).

comparisons, paired $t$-test was used to compare postnatal groups with corresponding prenatal-only treated groups. To test whether number of pulses changed significantly between pre- $\mathrm{E}_{2}\left(72 \mathrm{~h}\right.$ post-GnRH-A) and post- $\mathrm{E}_{2}$ period in each treatment groups, Wilcoxon signed-rank test was used. In addition, Cohen's effect size analysis was used as a secondary analysis to relate the magnitude of differences.

\section{$E_{2}$-positive feedback and periovulatory dynamics}

Comparisons involved peak time, peak hormone concentration, total hormone released during the surge, the duration of surge, and time from $E_{2}$ peak to $\mathrm{LH}$ peak. All continuous variables were log-transformed before analysis. For comparing categorical variables (\% synchronized and
$\%$ showing LH surges in the periovulatory dynamics study and $\%$ responded in the positive feedback study) between prenatal groups and each of the postnatal pairs, Fisher's exact test was used. For comparison of $\mathrm{LH}$ and FSH surge dynamics among only prenatal treatment groups, ANOVA was used followed by post hoc tests after adjusting for multiple comparisons. For variables with only one TS subject providing data in $\mathrm{E}_{2}$-positive feedback test or two TS subjects in periovulatory hormonal dynamics examination, given all other prenatal groups are not significantly different, the mean and standard deviation (SD) of the outcome using combined data from the $C, D, E_{2}$, and ED groups were first calculated. Then, the probability of observing a value larger or equal to the value observed in the single TS subject assuming it is drawn from a normal distribution with the above derived mean and SD was calculated. A smaller $P$-value indicates that TS subject was less likely to have the same distribution as other groups. SFor prenatal vs postnatal treatment comparisons, unpaired t-test was used.
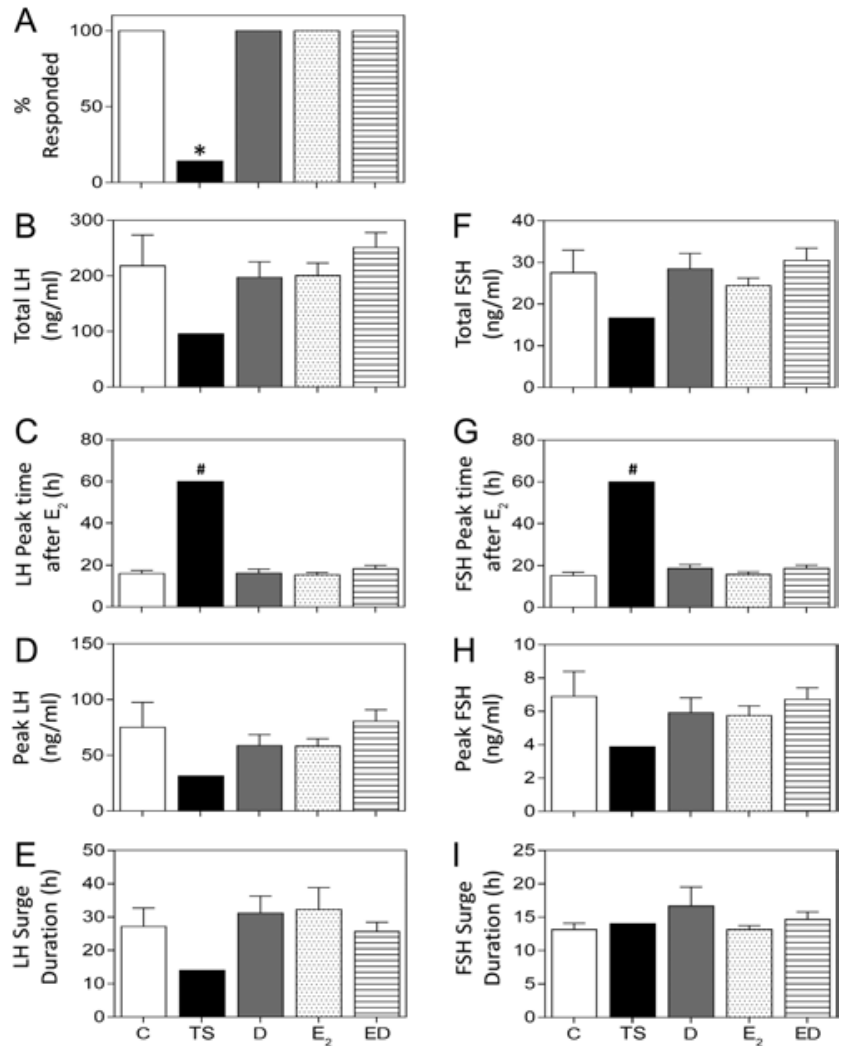

Figure 3 Gonadotropin surge characteristics (mean \pm S.E.M.) during the $E_{2}$-positive feedback test in prenatal-only-treated groups. (A) The percentage of animals that responded to $\mathrm{E}_{2}$-positive feedback test, (B) total $\mathrm{LH}$ secreted during the surge, $(\mathrm{C})$ time of $\mathrm{LH}$ surge peak after $\mathrm{E}_{2}$, (D) peak LH concentration, (E) duration of LH surge, (F) total FSH secreted during the surge, (G) time of FSH surge peak after $E_{2}$, (H) peak FSH concentration and (I) duration of FSH surge.

Observations in the TS-treated group are from a single animal that responded to the $E_{2}$-positive feedback challenge. Asterisks indicate significant difference from $\mathrm{C}$ and ${ }^{*}$ indicates a significant difference between the TS-animal and the composite of all treatment groups (see statistical analysis for modeling). 

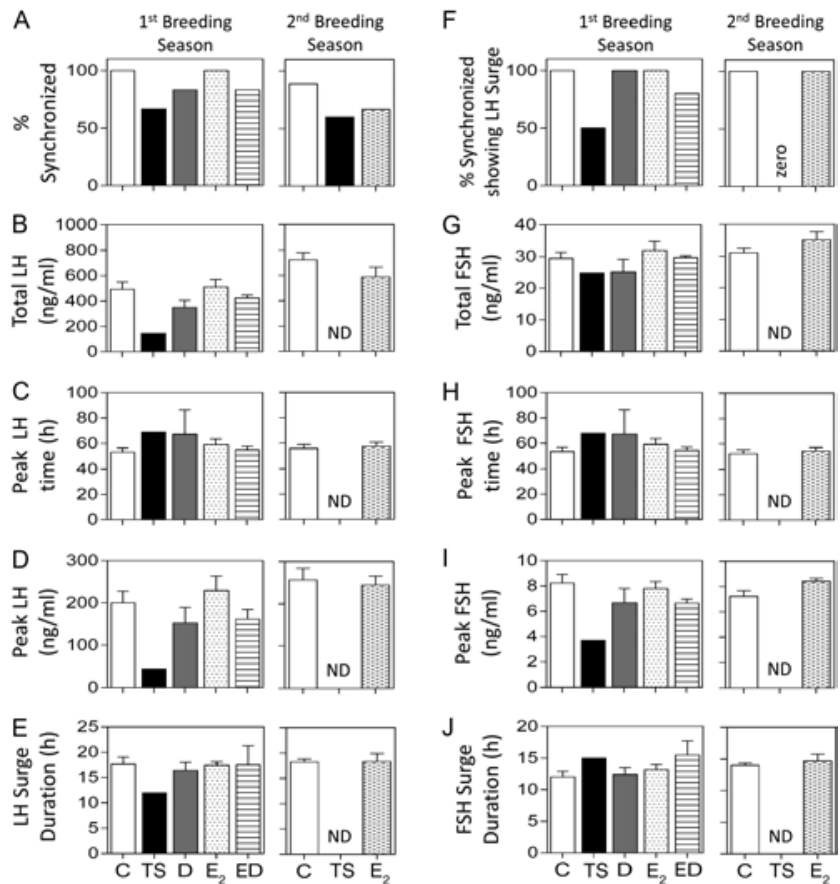

Figure 4 Periovulatory hormonal dynamics in prenatal treatment groups. (A) Results of the estrous synchronization, (B) total LH secreted during the surge, (C) time of LH surge peak, (D) peak LH concentration, (E) duration of LH surge, $(\mathrm{F})$ percentage of synchronized animals showing a definable LH surge, (G) total FSH secreted during the surge, $(\mathrm{H})$ time of FSH surge peak, $(\mathrm{I})$ peak FSH concentration and (J) duration of $\mathrm{FSH}$ surge from periovulatory hormonal studies during the first and second breeding seasons. Observations in the TS-treated group are mean from two animals that showed definable LH surge. \#indicates a significant difference between the TS-animal and the composite of all treatment groups. ND, no data available, as the animals in this group did not exhibit both primary gonadotropin surge.

\section{Results}

\section{Effects of prenatal treatments}

$E_{2}$-negative feedback responses

The results of the $E_{2}$-negative feedback study in animals that received only prenatal treatments are summarized in Fig. 2A and B, with representative circulating $\mathrm{LH}$ profiles shown in Supplementary Fig. 1, see section on supplementary data given at the end of this article. Administration of $\mathrm{GnRH}-\mathrm{A}$ reduced $\mathrm{E}_{2}$ concentrations to $\sim 0.3 \mathrm{pg} / \mathrm{mL}$ in all groups (data not shown). Approximately $72 \mathrm{~h}$ after the last injection of GnRH-A, endogenous $\mathrm{E}_{2}$ concentrations had increased slightly but were not statistically different among prenatal treatment groups (Fig. 2A, Pre E). Insertion of a $3 \mathrm{~mm} \mathrm{E}_{2}$ implant caused the concentration of $E_{2}$ to increase to $\sim 0.6 \mathrm{pg} / \mathrm{mL}$ across all prenatal treatment groups (Fig. 2A, Post E). Effect size analysis found a large size effect of $E_{2}$ implants in $\mathrm{C}, \mathrm{D}$, and $\mathrm{ED}$ groups, but not in TS and $\mathrm{E}_{2}$ groups. Administration of $\mathrm{GnRH}-\mathrm{A}$ reduced the $\mathrm{LH}$ pulsatility in all prenatal treatment groups (data not shown).
Seventy-two hours after cessation of GnRH-A injection, LH pulsatility increased in all prenatal treatment groups, and $\mathrm{LH}$ pulse frequency did not differ among groups (Fig. 2B, Pre $\mathrm{E}_{2}$ ). $\mathrm{E}_{2}$-treatment ablated $\mathrm{LH}$ pulses in $\mathrm{C}$ animals (Fig. 2B, Post $\mathrm{E}_{2}$ ). Prenatal TS-treated animals had significantly more $\mathrm{LH}$ pulses during the $\mathrm{E}_{2}$-treatment period than those of $\mathrm{C}$ females (Fig. 2B, Post $\mathrm{E}_{2}$ ). A reduction in $\mathrm{LH}$ pulses was evident in TS-, $\mathrm{D}_{-}$, and $E_{2}$-treated animals relative to pre $E_{2}$ period, albeit to a lesser degree than in $\mathrm{C}$ animals (Fig. 2B, Post $\mathrm{E}_{2}$ ). While not reaching statistical significance, five of six animals showed suppression following $\mathrm{E}_{2}$-treatment in the $\mathrm{ED}$ group (Fig. 2B, Post $\mathrm{E}_{2}$ ).

\section{Age at puberty}

The large number of treatment comparisons relative to the sample size precluded identification of statistical differences among prenatal groups (Fig. 2C). However, Cohen's analysis found a large size effect between $\mathrm{C}$ and prenatal TS, $\mathrm{E}_{2}$, and $\mathrm{ED}$ groups, but not $\mathrm{D}$ treatment.

\section{$E_{2}$-positive feedback responses}

Results of the $E_{2}$-positive feedback test in prenatal groups are summarized in Fig. 3 and representative hormonal profiles are depicted in Supplementary Fig. 2. While all females in the C and prenatal $D_{-}, E_{2}$ - and ED-treated groups demonstrated gonadotropin surges, only one prenatal TS-treated female responded to the $E_{2}$-positive feedback challenge (Fig. 3A). Mean total release (Fig. 3B and F), peak time (Fig. $3 \mathrm{C}$ and $\mathrm{G}$ ), peak concentrations (Fig. 3D and $\mathrm{H}$ ), and duration (Fig. 3E and $\mathrm{I}$ ) of the $\mathrm{LH} / \mathrm{FSH}$ surges did not differ among $\mathrm{C}, \mathrm{D}, \mathrm{E}_{2}$, and ED groups. The only prenatal TS-treated female that responded to the $E_{2}$-positive feedback showed a delayed and reduced gonadotropin surge.

\section{Periovulatory hormonal dynamics}

Results of the periovulatory hormonal dynamics during the first and second breeding season in prenatal groups are summarized in Fig. 4 and representative hormonal profiles are depicted in Supplementary Figs 3 and 4 respectively. During the first breeding season, $100 \%$ of the animals were synchronized in the $\mathrm{C}$ and $\mathrm{E}_{2}$ groups, while $66.7,83.3$, and $83.3 \%$ of the animals showed estrous synchronization following $\mathrm{PGF}_{2 \alpha}$ administration in TS, D, and ED groups respectively (Fig. 4A). Of the female sheep that synchronized, $100 \%$ of the animals showed $\mathrm{LH}$ surges in $\mathrm{C}, \mathrm{D}$, and $\mathrm{E}_{2}$ groups, while only two of four and four of five animals showed definable $\mathrm{LH}$ surges in the TS and ED groups respectively (Fig. 4F). No differences in mean total release (Fig. $4 \mathrm{~B}$ and $\mathrm{G}$ ), peak time (Fig. 4C and $\mathrm{H}$ ), peak gonadotropin concentration (Fig. 4D and I), and duration (Fig. 4E and J) were observed between $C, E_{2}, D$, and ED groups. Of the two 
prenatal TS-treated animals that met the criteria of an LH surge (sustained increase in LH for over $8 \mathrm{~h}$ ), total LH was lower than that of the control animals, but no difference was observed with other surge parameters.

During the second breeding season, 88.9, 60.0, and $66.7 \%$ of the animals from $\mathrm{C}_{-}, \mathrm{TS}-$, and $\mathrm{E}_{2}$-treatment groups synchronized following $\mathrm{PGF}_{2 \alpha}$ administration respectively (Fig. 4A). Of these, $100 \%$ of the animals in C and $E_{2}$ groups while none of the animals in the TS group showed definable LH surges (Fig. 4F). No differences in the gonadotropin surge characteristics were observed between $\mathrm{C}$ and $\mathrm{E}_{2}$ groups (Fig. 4B, C, D, E, G, H, I and J).

\section{Effects of postnatal $E_{2}$ exposure}

$E_{2}$ negative feedback responses

The impact of postnatal $E_{2}$-treatment on modulating the effects of prenatal steroid treatment on
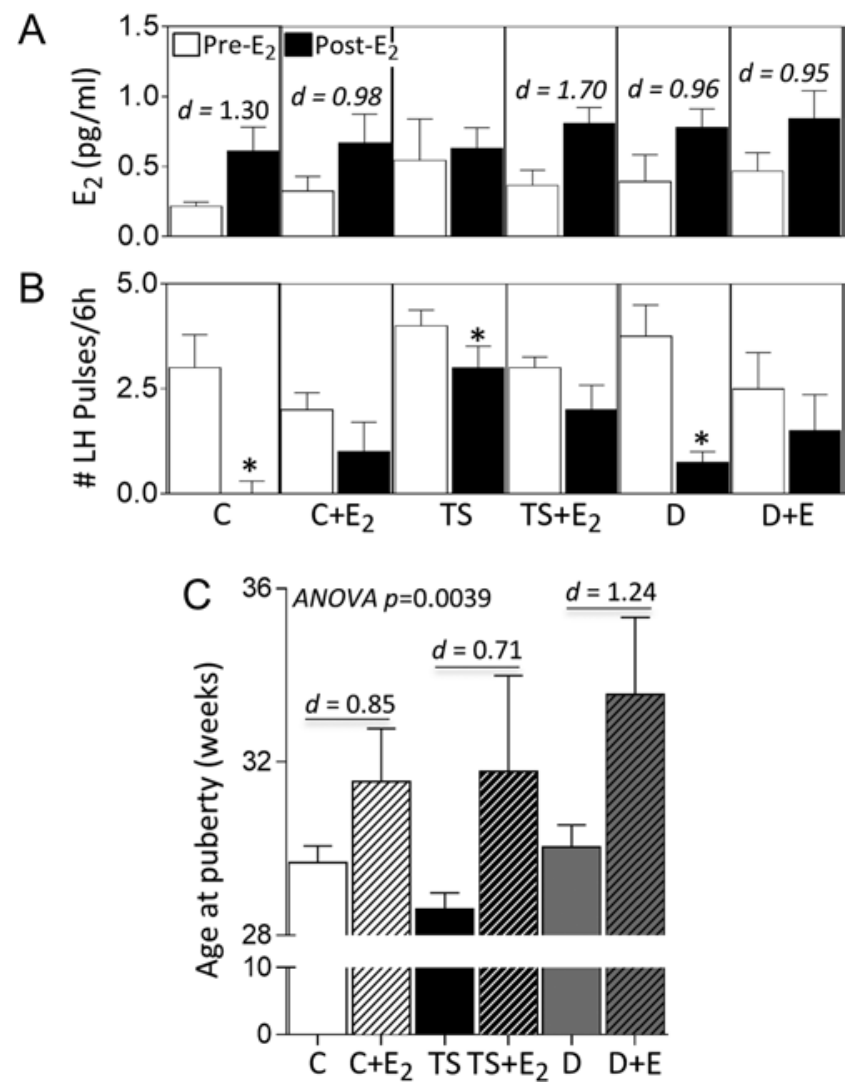

Figure 5 Results (mean \pm S.E.M.) of the $\mathrm{E}_{2}$-negative feedback test in postnatal groups are shown in panels $A$ and $B$ and age of puberty in panel C. Panel A shows the circulating concentrations of $E_{2}$ pre- and post- $E_{2}$ administration. Panel $B$ shows the number of $\mathrm{LH}$ pulses over a 6-h period pre- and post- $E_{2}$ administration. Asterisks indicate significant difference $(P<0.05)$ between pre- and post- $E_{2}$ periods within the respective treatment groups. Note the prenatal treatment-only groups C, TS, and D are repeated from respective panels from Fig. 2, to allow comparison between postnatal groups and prenatal-only groups. Cohen's $d$ values as determined by effect size analysis are shown in panels $A\left(P r e E_{2}\right.$ vs Post $E_{2}$ ) and $C$ (prenatal treatment vs postnatal $\mathrm{E}_{2}$ ).
$\mathrm{E}_{2}$-negative feedback is summarized in Fig. $5 \mathrm{~A}$ and $\mathrm{B}$ and representative circulating $\mathrm{LH}$ profiles in Supplementary Fig. 1. GnRH-A markedly reduced $E_{2}$ concentrations in the postnatal groups $\left(C+E_{2}, T S+E_{2}\right.$, and $\left.D+E\right)$ to $\sim 0.3 \mathrm{pg} / \mathrm{mL}$ (data not shown), and $E_{2}$ implant insertion increased concentrations of $\mathrm{E}_{2}$ to $\sim 0.6 \mathrm{pg} / \mathrm{mL}$ (Fig. $5 \mathrm{~A}$, Pre $\mathrm{E}_{2}$ ). Effect size analysis comparing postnatal $E_{2}$-treatment groups with corresponding prenatal-only treated groups showed large effects following $E_{2}$ implants. Suppression of $\mathrm{LH}$ pulsatility following GnRH-A treatment and an increase in the number of $\mathrm{LH}$ pulses following cessation of $\mathrm{GnRH}-\mathrm{A}$ treatment in the postnatal groups were similar to changes described for the prenatal treatmentonly groups. There were no differences in LH pulse frequency among treatment groups during pre- $\mathrm{E}_{2}$ period (Fig. 5B, Pre $E_{2}$ ). While $E_{2}$-treatment completely ablated $\mathrm{LH}$ pulsatility in the $\mathrm{C}$ group, this complete suppression was not achieved in four out of seven animals in the $\mathrm{C}+\mathrm{E}_{2}$ group, which had pulses during the pre- $\mathrm{E}_{2}$ period
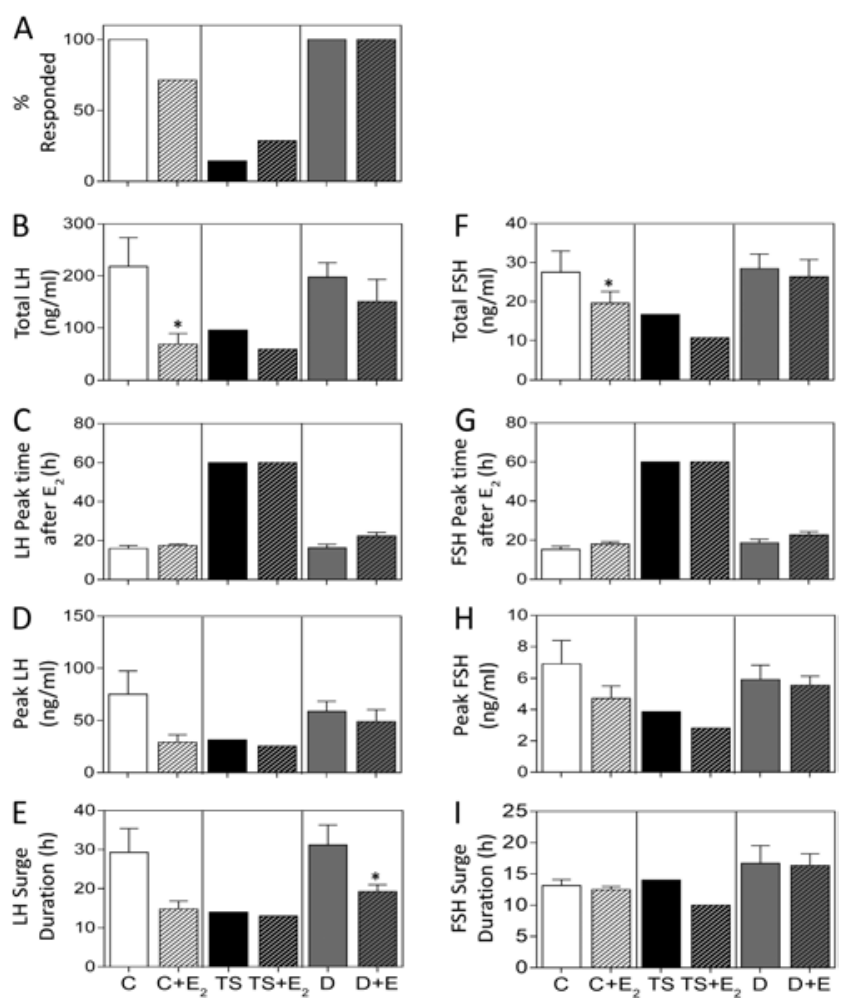

Figure 6 Gonadotropin surge characteristics (mean \pm S.E.M.) during the $E_{2}$-positive feedback test in postnatal groups. (A) The percentage of animals that responded to $\mathrm{E}_{2}$-positive feedback test, (B) total $\mathrm{LH}$ secreted during the surge, $(C)$ time of $\mathrm{LH}$ surge peak after $\mathrm{E}_{2}$, (D) peak $\mathrm{LH}$ concentration, (E) duration of $\mathrm{LH}$ surge, (F) total FSH secreted during the surge, (G) time of FSH surge peak after $E_{2},(H)$ peak FSH concentration and (I) duration of FSH surge. Data from postnatal groups were compared with the respective prenatal groups (data are repeated from Fig. 3 for comparison purposes). Observations in the TS-treated group are from a single animal, while TS $+E_{2}$ group is the mean of two animals that responded to the $E_{2}$-positive feedback challenge. Asterisks indicate significant differences $(P<0.05)$ between postnatal and prenatal groups. 
(Fig. 5B, Post $\mathrm{E}_{2}$ ). The remaining three animals had no $\mathrm{LH}$ pulses during the pre- $E_{2}$ period, but showed low pulse frequency $\left(1-2\right.$ pulses $/ 6 \mathrm{~h}$ ) during $\mathrm{E}_{2}$-treatment period. Postnatal $E_{2}$ failed to reduce $\mathrm{LH}$ pulsatility in TS $+\mathrm{E}_{2}$ and $\mathrm{D}+\mathrm{E}$ groups (Fig. $5 \mathrm{~B}$, Post $\mathrm{E}_{2}$ ) as opposed to suppressive effects being evident in prenatal TS- and D-only females.

Age at puberty

ANOVA revealed a significant postnatal $\mathrm{E}_{2}$-treatment effect in delaying age at puberty (Fig. 5C). Similarly, effect size analysis showed robust effects of postnatal $E_{2}$-treatment in delaying the age at puberty in all treated groups.

\section{$E_{2}$-positive feedback responses}

Results of the $E_{2}$-positive feedback test in the postnatal groups are summarized in Fig. 6 and Supplementary
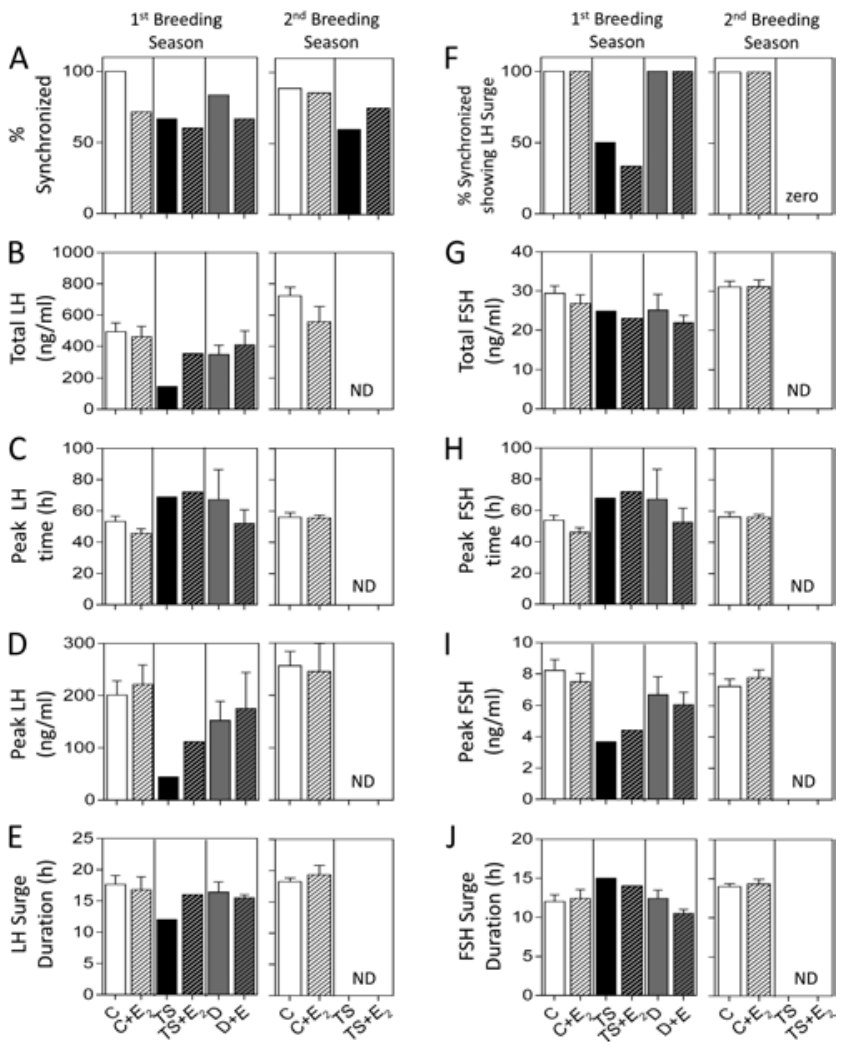

Figure 7 Effects of postnatal $E_{2}$-treatment on periovulatory hormonal dynamics. (A) Results of the estrous synchronization, (B) total LH secreted during the surge, $(C)$ time of $\mathrm{LH}$ surge peak, (D) peak $\mathrm{LH}$ concentration, (E) duration of LH surge, (F) percentage of synchronized animals showing a definable $\mathrm{LH}$ surge, $(\mathrm{G})$ total FSH secreted during the surge, (H) time of FSH surge peak, (I) peak FSH concentration and (J) duration of FSH surge from periovulatory hormonal studies in prenatal and postnatal treatment groups during the first and second breeding cycles are shown. Data from postnatal groups were compared with the respective prenatal groups (data are repeated from Fig. 4 for comparison purposes). Observations in the TS-treated group are mean from two animals and one animal in the TS $+E_{2}$ group that showed definable LH surge. ND, no data available, as none of the animals in this group had both primary gonadotropin surge.
Fig. 2. While five of seven $C+E_{2}$ and two of seven $\mathrm{TS}+\mathrm{E}_{2}$ animals responded to the positive feedback challenge, all $\mathrm{D}+\mathrm{E}$ females demonstrated a response (Fig. 6A). Except for a reduction in total $\mathrm{LH}$ and $\mathrm{FSH}$ released in response to postnatal $E_{2}$-treatment in the $\mathrm{C}+\mathrm{E}_{2}$ group (Fig. $6 \mathrm{~B}$ and $\mathrm{F}$ ), and surge duration in the $\mathrm{D}+\mathrm{E}$ group relative to corresponding prenatal control groups (Fig. 6E), postnatal $\mathrm{E}_{2}$-treatment had no effect on other $\mathrm{LH}$ and $\mathrm{FSH}$ surge parameters.

\section{Periovulatory hormonal dynamics}

The impact of postnatal $E_{2}$-treatment on periovulatory hormonal dynamics during the first and second breeding season is summarized in Fig. 7, and representative hormonal profiles are depicted in Supplementary Figs 3 and 4 respectively. Among the animals that received postnatal $\mathrm{E}_{2}$-treatment, $71.4 \%$ of $\mathrm{C}+\mathrm{E}_{2}, 60.0 \%$ of $\mathrm{TS}+\mathrm{E}_{2}$, and $66.7 \%$ of the D+E animals showed estrous synchronization following PGF $_{2 \alpha}$ administration during the first breeding season (Fig. 7A). Of those that synchronized, 100\% of the animals showed definable LH surges in $\mathrm{C}+\mathrm{E}_{2}$ and $\mathrm{D}+\mathrm{E}$ groups, while only 1 of the 3 animals that synchronized had an LH surge in the TS $+E_{2}$ group (Fig. 7F). Postnatal $E_{2}$-treatment had no effect on any of the attributes of the preovulatory surge dynamics (Fig. 7). Because only one $\mathrm{TS}+\mathrm{E}_{2}$ animal had a definable $\mathrm{LH}$ surge, comparison between TS and TS $+E_{2}$ animals was not possible.

During the second breeding season, 85.7 and $75.0 \%$ of the animals in $C+E_{2}$ and $T S+E_{2}$ treatment groups synchronized following $\mathrm{PGF}_{2 \alpha}$ administration respectively (Fig. $7 \mathrm{~A}$ ). Of these, $100 \%$ of the $C+E_{2}$ and none of the TS $+E_{2}$ animals showed definable LH surges (Fig. 7F). Postnatal $E_{2}$-treatment had no effect on any of the parameters of preovulatory surge dynamics in $\mathrm{C}$ animals, and since TS $+E_{2}$ animals did not surge, such comparisons were not possible (Fig. 7).

\section{Discussion}

The results from this study confirm our previous findings of neuroendocrine feedback, pubertal timing, and periovulatory disruptions in prenatal TS-treated female sheep. However, the data fail to support our hypotheses that (1) prenatal $E_{2}$-treatment replicates the neuroendocrine disruptions attributed to estrogenic programming of $E_{2}$-positive feedback and periovulatory hormonal dynamics in prenatal TS-treated females and (2) concomitant prenatal treatment with $\mathrm{D}$ and $\mathrm{E}_{2}$ reproduces the $E_{2}$ neuroendocrine feedback and periovulatory defects induced by prenatal TS excess. Furthermore, our results indicate that postnatal $E_{2}$-treatment (1) reduces the $E_{2}$ inhibitory effects on tonic $\mathrm{LH}$ release in prenatal TS and D groups, (2) delays the onset of puberty in all groups, and (3) fails to amplify the dampening of LH/FSH surges during the $E_{2}$-positive feedback challenge in prenatal TS- and D-treated animals. The significance of these 
findings and their relevance to the understanding of the steroid component in programming these neuroendocrine feedback disruptions are discussed below.

\section{Estrogenic regulation of prenatal TS-induced disruptions}

Our previous findings showing lack of disruptions in $\mathrm{E}_{2^{-}}$ positive feedback and periovulatory hormonal dynamics in prenatal D-treated sheep (Veiga-Lopez et al. 2009) and failure of androgen antagonist cotreatment to prevent $E_{2}$-positive feedback disruptions induced by prenatal TS-treatment (Abi Salloum et al. 2012) are consistent with the premise that these defects are mediated by estrogenic programming stemming from aromatization of TS to $E_{2}$. Paradoxically, the present observations that prenatal $\mathrm{E}_{2}$-treatment did not result in $E_{2}$-positive feedback and periovulatory disruptions fail to support this premise. One possibility for this discrepancy is that not sufficient fetal $E_{2}$ concentrations were achieved. Alternatively, these findings, in concert with previous findings of partial restoration of preovulatory LH surges in animals cotreated with TS and androgen antagonist (Padmanabhan et al. 2015), raise the possibility that both androgens and estrogens synergize in programming the prenatal TS-induced disruptions in $\mathrm{E}_{2}$ feedback and periovulatory hormonal dynamics.

Similarly, the failure of concomitant treatment with $E_{2}$ and $D$ to replicate the reproductive neuroendocrine defects might also be a function of inadequate estrogen levels achieved and consequent imbalance in androgen to estrogen ratio at the fetal level relative to what is attained with TS-treatment alone. An altered androgen to estrogen ratio could arise from insufficient estrogen levels being achieved due to placental metabolism of the peripherally administered $E_{2}$ to lesser active metabolites as seen in monkeys (Slikker et al. 1982) or from increased androgen actions, since D has higher potency than TS (Grino et al. 1990). The ratio could also be altered, as D can be metabolized to $3 \beta$-diol, an estrogen receptor $\beta$ agonist (Handa et al. 2008). Therefore, additional studies involving the use of estrogen antagonist alone or in combination with an androgen antagonist are required to clearly address the relative role of androgens and estrogens in mediating these effects.

\section{Effects of postnatal $E_{2}$ exposure}

The lack of response to the $E_{2}$-negative feedback challenge in control animals postnatally treated with $E_{2}$ may be attributed to the downregulation of the estrogen receptor in the hypothalamus and pituitary gland due to continuous exposure to $E_{2}$. In fact, $E_{2}$-induced downregulation of estrogen receptor expression has been observed in other tissues, such as the uterus (Medlock et al. 1991, Farnell \& Ing 2003). Therefore, the interval between the removal of the postnatal $E_{2}$ implants and the $E_{2}$-negative feedback challenge ( 7 days) may have been insufficient to allow recovery of estrogen receptor expression in the hypothalamus and pituitary to facilitate responsiveness to the $E_{2}$-negative feedback challenge. Considering that puberty was delayed in postnatal $E_{2}$-treated animals, this lack of $E_{2}$-negative feedback response was surprising. To what extent this relates to the short interval between the removal of postnatal $E_{2}$ implant and the $E_{2}$-negative feedback testing remains to be determined. One possibility is that the delay in puberty could be a function of reduced gonadotropic support to the ovary (Foster et al. 1986).

Diminished gonadotropin release in response to $E_{2}-$ positive feedback was observed in prepubertal female sheep chronically treated with $E_{2}$ in this study and in previous studies (Malcolm et al. 2006). However, a reduction in the periovulatory release of gonadotropins was not observed when examined during the first and second breeding season. The reason for this difference might relate to the heightened sensitivity of prepubertal females to $E_{2}$-negative feedback compared with postpubertal females, resulting in reduced storage of $\mathrm{LH}$ in the pituitary that is available for release during the $\mathrm{E}_{2}$-positive feedback challenge. In contrast to normal periovulatory LH release in our study, postnatal exposure to $E_{2}$ was found to block endogenous LH surge in female sheep (Ozturk et al. 1998). The differences in LH surge responses between this study and our study may be a function of the circulating $E_{2}$ concentrations achieved by the treatment and/or the timing of treatment.

\section{Postnatal $E_{2}$ modulation of prenatal steroid effects}

Comparison of the effects of prenatal TS plus postnatal $E_{2}$-treatment with prenatal TS-treatment alone found that postnatal $E_{2}$-treatment does not amplify the effects of prenatal TS-treatment in reducing responsiveness to $E_{2}$-negative feedback and advancing puberty, a finding consistent with our previous studies (Sarma et al. 2005, Veiga-Lopez et al. 2009, Padmanabhan et al. 2015). Instead, postnatal $E_{2}$-treatment delayed puberty relative to controls, while failing to reduce gonadotropin levels in response to the $E_{2}$-negative feedback challenge. Considering that an escape from $E_{2}$-negative feedback is an important event controlling the onset of puberty, this dissociation between delayed puberty and reduced sensitivity to $E_{2}$-negative feedback is paradoxical. As discussed above, this dissociation may be a function of the short interval between the removal of the $E_{2}$ implant and the testing for the $E_{2}$-negative feedback.

Furthermore, the finding that $\mathrm{E}_{2}$-positive feedback and periovulatory hormonal dynamics were impaired in prenatal TS-treated sheep, which is in agreement with our previous findings (Sharma et al. 2002, Veiga-Lopez et al. 2009, Padmanabhan et al. 2015), coupled with failure of postnatal $E_{2}$ exposure to amplify these disruptions, 
suggests these defects are organized primarily during the prenatal life, with little or no impact of continuous postnatal exposure to excess $E_{2}$, at least at the dose tested. Alternatively, low concentrations of $E_{2}$ produced by the ovary during postnatal life may be sufficient to further differentiate (masculinize) the $\mathrm{GnRH} /$ gonadotropin surge mechanism in ovary-intact, prenatal TS-treated female sheep, with exogenous postnatal $\mathrm{E}_{2}$-treatment having no additional impact on the gonadotropin surges. This possibility is supported by the observation that neonatal ovariectomy restores the $\mathrm{E}_{2}$-induced $\mathrm{LH}$ surge in prenatal TS-treated sheep (Jackson et al. 2013).

Contrary to our expectation and in disagreement with our previous studies (Veiga-Lopez et al. 2009), prenatal D-treatment failed to disrupt $\mathrm{E}_{2}$-negative feedback. The reason for this discrepancy is unclear, but it may involve the different ages at which the $E_{2}$-negative feedback tests were carried out, suggesting that the desensitization to the $E_{2}$-negative feedback may occur only at a later developmental stage in D-treated compared with TS-treated females. As prenatal D-treated animals do not develop a multifollicular ovarian morphology (Smith et al. 2009), the delay in the desensitization of the neuroendocrine axis to the $E_{2}$-negative feedback could be due to lower secretion of $E_{2}$ and/or other ovarianderived factors unlike prenatal TS-treated females. Failure of postnatal $E_{2}$ to alter the $E_{2}$-positive feedback or periovulatory hormonal dynamics in prenatal D-treated animals is again consistent with such defects being programmed primarily during the prenatal life.

\section{Conclusions}

In conclusion, the results from this study combined with our earlier findings indicate that disruptions in $E_{2}$ feedback mechanisms, timing of puberty, and periovulatory hormonal dynamics seen in prenatal TS-treated sheep require activation of both androgenic and estrogenic pathways. Additionally, the present findings indicate that these neuroendocrine disruptions are programmed primarily during the prenatal life and are not amplified or modified by postnatal exposure to $E_{2}$ excess, at least at the dose tested. Unfortunately, likely due to a putative metabolism of $\mathrm{D}$ into $3 \beta$-diol or insufficient fetal $E_{2}$ concentrations achieved, the relative role of androgens or estrogens in programming some of these reproductive neuroendocrine defects could not be completely discerned by this study. In the future, comparative experiments utilizing antagonists of androgen and estrogen receptors separately and in combination need to be undertaken in both the ovariectomized and ovary-intact models. Although postnatal $E_{2}$ exposure did not amplify the adverse effects of prenatal TS exposure, it did negatively affect the timing of puberty and preovulatory gonadotropin release in control animals. These data indicate that postnatal exposure to EDC with estrogenic properties, through activational effects, may have the potential to adversely affect reproductive neuroendocrine function in females. Therefore, although extrapolation of findings in this sheep model to human pathology should be done cautiously, these observations highlight the potential for gestational and postnatal endocrine imbalances to negatively impact the offspring's reproductive health.

\section{Supplementary data}

This is linked to the online version of the paper at http://dx.doi. org/10.1530/REP-16-0065.

\section{Declaration of interest}

The authors declare that there is no conflict of interest that could be perceived as prejudicing the impartiality of the research reported.

\section{Funding}

This work was supported by National Institutes of Health grant P01 HD44232.

\section{Acknowledgments}

We are grateful to Mr Douglas Doop for his expert animal care, facility management, and help with generation of the experimental lambs; Drs Mohan Manikkam and Teresa Steckler, Ms Jasmine Tavadia, Mr James Lee, Mr Rohit Sreedharan, staff, and undergraduate students from Dr Theresa Lee's laboratory and students from University of Michigan Undergraduate Research Opportunity program (UROP) for assistance with prenatal steroid treatment, blood sampling, hormonal assays, and data analyses. We are also thankful to Dr Aimee K Wurst from the laboratory of Dr Keith Inskeep for performing the estradiol measures at West Virginia University, Dr Wen Ye for the help with statistical analysis, and Mr Jacob Moeller for proof-reading and editing the language.

\section{References}

Abi Salloum B, Herkimer C, Lee JS, Veiga-Lopez A \& Padmanabhan V 2012 Developmental programming: prenatal and postnatal contribution of androgens and insulin in the reprogramming of estradiol positive feedback disruptions in prenatal testosterone-treated sheep. Endocrinology 153 2813-2822. (doi:10.1210/en.2011-2074)

Bahrke MS, Yesalis CE \& Brower KJ 1998 Anabolic-androgenic steroid abuse and performance-enhancing drugs among adolescents. Child and Adolescent Psychiatric Clinics of North America 7 821-838.

Barker DJ 2004 The developmental origins of adult disease. Journal of the American College of Nutrition 23 588S-595S. (doi:10.1080/07315724. 2004.10719428)

Bayer TA, Falkai P \& Maier W 1999 Genetic and non-genetic vulnerability factors in schizophrenia: the basis of the "two hit hypothesis." Journal of Psychiatric Research 33 543-548. (doi:10.1016/S00223956(99)00039-4)

Birch RA, Padmanabhan V, Foster DL, Unsworth WP \& Robinson JE 2003 Prenatal programming of reproductive neuroendocrine function: fetal androgen exposure produces progressive disruption of reproductive 
cycles in sheep. Endocrinology 144 1426-1434. (doi:10.1210/ en.2002-220965)

Clarke I, Scaramuzzi R \& Short R 1977 Ovulation in prenatally androgenized ewes. Journal of Endocrinology 73 385-389. (doi:10.1677/ joe.0.0730385)

Cohen J 1992 A power primer. Psychological Bulletin 112 155-159. (doi:10.1037/0033-2909.112.1.155)

Diamanti-Kandarakis E, Bourguignon JP, Giudice LC, Hauser R, Prins GS, Soto AM, Zoeller RT \& Gore AC 2009 Endocrine-disrupting chemicals: an Endocrine Society scientific statement. Endocrine Reviews $\mathbf{3 0}$ 293-342. (doi:10.1210/er.2009-0002)

Dumesic DA, Goodarzi MO, Chazenbalk GD \& Abbott DH 2014 Intrauterine environment and polycystic ovary syndrome. Seminars in Reproductive Medicine 32 159-165. (doi:10.1055/s-0034-1371087)

Farnell YZ \& Ing NH 2003 The effects of estradiol and selective estrogen receptor modulators on gene expression and messenger RNA stability in immortalized sheep endometrial stromal cells and human endometrial adenocarcinoma cells. Journal of Steroid Biochemistry and Molecular Biology 84 453-461. (doi:10.1016/S0960-0760(03)00066-9)

Foster DL \& Jackson LM 2006 Puberty in the sheep. In Knobil and Neill's Physiology of Reproduction, pp 2127-2176. Boston, MA, USA: Elsevier.

Foster DL, Ryan KD, Goodman RL, Legan SJ, Karsch FJ \& Yellon SM 1986 Delayed puberty in lambs chronically treated with oestradiol. Journal of Reproduction and Fertility 78 111-117. (doi:10.1530/jrf.0.0780111)

Foster DL, Jackson LM \& Padmanabhan V 2006 Programming of GnRH feedback controls timing puberty and adult reproductive activity. Molecular and Cellular Endocrinology 254-255 109-119. (doi:10.1016/j. mce.2006.04.004)

Goodman RL, Legan SJ, Ryan KD, Foster DL \& Karsch FJ 1980 Two effects of estradiol that normally contribute to the control of tonic LH secretion in the ewe. Biology of Reproduction 23 415-422. (doi:10.1095/ biolreprod23.2.415)

Goodman RL, Legan SJ, Ryan KD, Foster DL \& Karsch FJ 1981 Importance of variations in behavioural and feedback actions of oestradiol to the control of seasonal breeding in the ewe. Journal of Endocrinology $\mathbf{8 9}$ 229-240. (doi:10.1677/joe.0.0890229)

Grino PB, Griffin JE \& Wilson JD 1990 Testosterone at high concentrations interacts with the human androgen receptor similarly to dihydrotestosterone. Endocrinology 126 1165-1172. (doi:10.1210/ endo-126-2-1165)

Handa RJ, Pak TR, Kudwa AE, Lund TD \& Hinds L 2008 An alternate pathway for androgen regulation of brain function: activation of estrogen receptor beta by the metabolite of dihydrotestosterone, 5alphaandrostane-3beta,17beta-diol. Hormones and Behavior 53 741-752. (doi:10.1016/j.yhbeh.2007.09.012)

Jackson LM, Timmer KM \& Foster DL 2008 Sexual differentiation of the external genitalia and the timing of puberty in the presence of an antiandrogen in sheep. Endocrinology 149 4200-4208. (doi:10.1210/ en.2007-1382)

Jackson LM, Mytinger A, Roberts EK, Lee TM, Foster DL, Padmanabhan V \& Jansen HT 2013 Developmental programming: postnatal steroids complete prenatal steroid actions to differentially organize the $\mathrm{GnRH}$ surge mechanism and reproductive behavior in female sheep. Endocrinology 154 1612-1623. (doi:10.1210/en.20121613)

Jefferson WN, Patisaul HB \& Williams CJ 2012 Reproductive consequences of developmental phytoestrogen exposure. Reproduction 143 247-260. (doi:10.1530/REP-11-0369)

Jensen ET, Daniels JL, Sturmer T, Robinson WR, Williams CJ, Vejrup K, Magnus P \& Longnecker MP 2015 Hormonal contraceptive use before and after conception in relation to preterm birth and small for gestational age: an observational cohort study. BJOG 122 1349-1361. (doi:10.1111/ bjo.2015.122.issue-10)

Karsch FJ, Dahl GE, Evans NP, Manning JM, Mayfield KP, Moenter SM \& Foster DL 1993 Seasonal changes in gonadotropinreleasing hormone secretion in the ewe: alteration in response to the negative feedback action of estradiol. Biology of Reproduction 49 13771383. (doi:10.1095/biolreprod49.6.1377)

Malcolm KD, Jackson LM, Bergeon C, Lee TM, Padmanabhan V \& Foster DL 2006 Long-term exposure of female sheep to physiologic concentrations of estradiol: effects on the onset and maintenance of reproductive function, pregnancy, and social development in female offspring. Biology of Reproduction 75 844-852. (doi:10.1095/biolreprod.106.053264)

Manikkam M, Crespi EJ, Doop DD, Herkimer C, Lee JS, Yu S, Brown MB, Foster DL \& Padmanabhan V 2004 Fetal programming: prenatal testosterone excess leads to fetal growth retardation and postnatal catch-up growth in sheep. Endocrinology 145 790-798. (doi:10.1210/ en.2003-0478)

Manikkam M, Steckler TL, Welch KB, Inskeep EK \& Padmanabhan V 2006 Fetal programming: prenatal testosterone treatment leads to follicular persistence/luteal defects; partial restoration of ovarian function by cyclic progesterone treatment. Endocrinology 147 1997-2007. (doi:10.1210/ en.2005-1338)

Medlock KL, Lyttle CR, Kelepouris N, Newman ED \& Sheehan DM 1991 Estradiol down-regulation of the rat uterine estrogen receptor. Proceedings of The Society for Experimental Biology and Medicine 196 293-300. (doi:10.3181/00379727-196-43191)

Nakagawa S \& Cuthill IC 2007 Effect size, confidence interval and statistical significance: a practical guide for biologists. Biological Reviews of the Cambridge Philosophical Society 82 591-605. (doi:10.1111/ brv.2007.82.issue-4)

New MI 2006 Extensive clinical experience: nonclassical 21-hydroxylase deficiency. Journal of Clinical Endocrinology \& Metabolism 914205 4214. (doi: 10.1210/jc.2006-1645)

Niswender GD, Reichert LE Jr, Midgley AR Jr \& Nalbandov AV 1969 Radioimmunoassay for bovine and ovine luteinizing hormone. Endocrinology 84 1166-1173. (doi:10.1210/endo-84-5-1166)

Ozturk M, Smith RF \& Dobson H 1998 Effect of prolonged exposure to oestradiol on subsequent LH secretion in ewes. Journal of Reproduction and Fertility 114 1-9. (doi:10.1530/jrf.0.1140001)

Padmanabhan V \& Veiga-Lopez A 2013a Animal models of the polycystic ovary syndrome phenotype. Steroids 78 734-740. (doi:10.1016/j. steroids.2013.05.004)

Padmanabhan V \& Veiga-Lopez A $2013 b$ Sheep models of polycystic ovary syndrome phenotype. Molecular and Cellular Endocrinology 373 8-20. (doi:10.1016/j.mce.2012.10.005)

Padmanabhan V, Evans NP, Dahl GE, McFadden KL, Mauger DT \& Karsch FJ 1995 Evidence for short or ultrashort loop negative feedback of gonadotropin-releasing hormone secretion. Neuroendocrinology 62 248-258. (doi:10.1159/000127011)

Padmanabhan V, McFadden K, Mauger DT, Karsch FJ \& Midgley AR Jr 1997 Neuroendocrine control of follicle-stimulating hormone (FSH) secretion. I. Direct evidence for separate episodic and basal components of FSH secretion. Endocrinology 138 424-432. (doi:10.1210/endo.138.1.4892)

Padmanabhan V, Veiga-Lopez A, Herkimer C, Abi Salloum B, Moeller J, Beckett E \& Sreedharan R 2015 Developmental programming: prenatal and postnatal androgen antagonist and insulin sensitizer interventions prevent advancement of puberty and improve LH surge dynamics in prenatal testosterone-treated sheep. Endocrinology 156 2678-2692. (doi:10.1210/en.2015-1235)

Peretz J, Vrooman L, Ricke WA, Hunt PA, Ehrlich S, Hauser R, Padmanabhan V, Taylor HS, Swan SH, VandeVoort CA et al. 2014 Bisphenol a and reproductive health: update of experimental and human evidence, 2007-2013. Environmental Health Perspectives 122 775-786. (doi:10.1289/ehp.1307728)

Pignatelli D 2013 Non-classic adrenal hyperplasia due to the deficiency of 21-hydroxylase and its relation to polycystic ovarian syndrome. Frontiers of Hormone Research 40 158-170. (doi:10.1159/000342179)

Puttabyatappa M, Cardoso RC \& Padmanabhan V 2015 Effect of maternal PCOS and PCOS-like phenotype on the offspring's health. Molecular and Cellular Endocrinology In press. (doi:10.1016/j.mce.2015.11.030)

Rhind SM, Rae MT \& Brooks AN 2001 Effects of nutrition and environmental factors on the fetal programming of the reproductive axis. Reproduction 122 205-214. (doi:10.1530/rep.0.1220205)

Robinson JE, Birch RA, Foster DL \& Padmanabhan V 2002 Prenatal exposure of the ovine fetus to androgens sexually differentiates the steroid feedback mechanisms that control gonadotropin releasing hormone secretion and disrupts ovarian cycles. Archives of Sexual Behavior 31 35-41. (doi:10.1023/A:1014075016956)

Rosenfield RL 2007 Clinical review: identifying children at risk for polycystic ovary syndrome. Journal of Clinical Endocrinology \& Metabolism 92 787-796. (doi:10.1210/jc.2006-2012) 
Rozell TG \& Keisler DH 1990 Effects of oestradiol on LH, FSH and prolactin in ovariectomized ewes. Journal of Reproduction and Fertility 88 645-653. (doi:10.1530/jrf.0.0880645)

Sarma HN, Manikkam M, Herkimer C, Dell'Orco J, Welch KB, Foster DL \& Padmanabhan V 2005 Fetal programming: excess prenatal testosterone reduces postnatal luteinizing hormone, but not folliclestimulating hormone responsiveness, to estradiol negative feedback in the female. Endocrinology 146 4281-4291. (doi:10.1210/en.2005-0322)

Schug TT, Janesick A, Blumberg B \& Heindel JJ 2011 Endocrine disrupting chemicals and disease susceptibility. Journal of Steroid Biochemistry and Molecular Biology 127 204-215. (doi:10.1016/j.jsbmb.2011.08.007)

Schulz KM, Molenda-Figueira HA \& Sisk CL 2009 Back to the future: the organizational-activational hypothesis adapted to puberty and adolescence. Hormones and Behavior 55 597-604. (doi:10.1016/j. yhbeh.2009.03.010)

Sharma TP, Herkimer C, West C, Ye W, Birch R, Robinson JE, Foster DL \& Padmanabhan V 2002 Fetal programming: prenatal androgen disrupts positive feedback actions of estradiol but does not affect timing of puberty in female sheep. Biology of Reproduction $\mathbf{6 6}$ 924-933. (doi:10.1095/biolreprod66.4.924)

Sir-Petermann T, Maliqueo M, Angel B, Lara HE, PerezBravo F \& Recabarren SE 2002 Maternal serum androgens in pregnant women with polycystic ovarian syndrome: possible implications in prenatal androgenization. Human Reproduction 17 2573-2579. (doi:10.1093/humrep/17.10.2573)

Slikker W Jr, Hill DE \& Young JF 1982 Comparison of the transplacental pharmacokinetics of 17 beta-estradiol and diethylstilbestrol in the subhuman primate. Journal of Pharmacology and Experimental Therapeutics 221 173-182.

Smith P, Steckler TL, Veiga-Lopez A \& Padmanabhan V 2009 Developmental programming: differential effects of prenatal testosterone and dihydrotestosterone on follicular recruitment, depletion of follicular reserve, and ovarian morphology in sheep. Biology of Reproduction $\mathbf{8 0}$ 726-736. (doi:10.1095/biolreprod.108.072801)

Steckler TL, Lee JS, Ye W, Inskeep EK \& Padmanabhan V 2008 Developmental programming: exogenous gonadotropin treatment rescues ovulatory function but does not completely normalize ovarian function in sheep treated prenatally with testosterone. Biology of Reproduction 79 686-695. (doi:10.1095/biolreprod.108.068643)

Steckler TL, Herkimer C, Dumesic DA \& Padmanabhan V 2009 Developmental programming: excess weight gain amplifies the effects of prenatal testosterone excess on reproductive cyclicity - implication for polycystic ovary syndrome. Endocrinology 150 1456-1465. (doi:10.1210/en.2008-1256)

Tang WY \& Ho SM 2007 Epigenetic reprogramming and imprinting in origins of disease. Reviews in Endocrine and Metabolic Disorders 8 173-182. (doi:10.1007/s11154-007-9042-4)
Tang WY, Newbold R, Mardilovich K, Jefferson W, Cheng RY, Medvedovic M \& Ho SM 2008 Persistent hypomethylation in the promoter of nucleosomal binding protein 1 (Nsbp1) correlates with overexpression of Nsbp1 in mouse uteri neonatally exposed to diethylstilbestrol or genistein. Endocrinology 149 5922-5931. (doi:10.1210/en.2008-0682)

Unsworth WP, Taylor JA \& Robinson JE 2005 Prenatal programming of reproductive neuroendocrine function: the effect of prenatal androgens on the development of estrogen positive feedback and ovarian cycles in the ewe. Biology of Reproduction 72 619-627. (doi:10.1095/ biolreprod.104.035691)

Vaiserman A 2014 Early-life exposure to endocrine disrupting chemicals and later-life health outcomes: an epigenetic bridge? Aging and Disease 5 419-429. (doi:10.14336/AD.2014.0500419)

Veiga-Lopez A, Ye W, Phillips DJ, Herkimer C, Knight PG \& Padmanabhan V 2008 Developmental programming: deficits in reproductive hormone dynamics and ovulatory outcomes in prenatal, testosteronetreated sheep. Biology of Reproduction 78 636-647. (doi:10.1095/ biolreprod.107.065904)

Veiga-Lopez A, Astapova OI, Aizenberg EF, Lee JS \& Padmanabhan V 2009 Developmental programming: contribution of prenatal androgen and estrogen to estradiol feedback systems and periovulatory hormonal dynamics in sheep. Biology of Reproduction 80 718-725. (doi:10.1095/ biolreprod.108.074781)

Veiga-Lopez A, Wurst AK, Steckler TL, Ye W \& Padmanabhan V 2014 Developmental programming: postnatal estradiol amplifies ovarian follicular defects induced by fetal exposure to excess testosterone and dihydrotestosterone in sheep. Reproductive Sciences 21 444-455. (doi:10.1177/1933719113503412)

Veldhuis JD \& Johnson ML 1986 Cluster analysis: a simple, versatile, and robust algorithm for endocrine pulse detection. American Journal of Physiology 250 E486-E493.

Wood RI \& Foster DL 1998 Sexual differentiation of reproductive neuroendocrine function in sheep. Reviews of Reproduction 3 130-140. (doi:10.1530/ror.0.0030130)

Wood RI, Ebling FJ, I'Anson H, Bucholtz DC, Yellon SM \& Foster DL 1991 Prenatal androgens time neuroendocrine sexual maturation. Endocrinology 128 2457-2468. (doi:10.1210/endo-128-5-2457)

Received 5 February 2016

First decision 21 March 2016

Revised manuscript received 25 April 2016

Accepted 23 May 2016 